\title{
Your Place or Mine: status and identity, space and place
}

\author{
Chris Simpson, University of St Mark and St John \\ Email: csimpson@marjon.ac.uk \\ DOI: http://dx.doi.org/10.5456/WPLL.17.4.4
}

\begin{abstract}
This paper takes as its starting point an action research project which sought to reinvigorate a Research and Practice network whose members included both community-based practitioners and academic staff at a University College. It focuses particularly on one aspect of network functioning which emerged during the research process, that is the influence of the settings in which meetings were held; and uses Bourdieu's concept of habitus to discuss ways in which academic and community settings may have impacted on members' participation. The paper incorporates understandings of space and place taken from Massey (2005) alongside symbolic capital (Bourdieu 1989) in order to discuss some of the implications of socially relational space as experienced at meetings of this Research and Practice Network. It discusses network functioning in different settings (both face-to-face and virtual) and concludes with a consideration of the significance of academic spaces for members of the practitioner community.
\end{abstract}

Key Words: Place and space, habitus, participation, networks

\section{Environment, Perception and Behaviour}

The subjective, embodied experience of environment and its influence on behaviour falls within the compass of a wide range of academic disciplines including social geography, environmental psychology, anthropology and sociology. Lewin, one of the early developers of environmental psychology, belonged to the Berlin school of Gestalt psychology, and so shared the understanding that subjective, multidimensional experiences are structured and organised by individuals as part of a sense-making process. He coined the term 'psychological ecology' (1943) to describe the interaction of a person with their environment. 'Lifespace' was understood by Lewin (1948) to denote the individual's subjective perception of themself within their environment - which could include the emotional tone or 'atmosphere'- at a given moment in time. Barker (1968) developed these ideas further in research on behaviour setting analysis, where he found a congruence of human behaviour with particular environments. Harre (1993) in further development of this research, elaborated role-rule contexts in which behaviour was found to be powerfully determined by setting and particularly so in the case of formal settings; he noted that 'physical settings are not neutral... (they) broadcast messages of reassurance and threat (1993:150). The discussion that follows attempts to understand the settings in which meetings of a Research and Practice Network (RAPN) took place, as spaces shaped both by social relations and by the materiality of the setting.

Bourdieu's (1977) concept of habitus provides a useful framework for appreciating how individuals' life histories, brought to a given situation, can (largely 
unconsciously) shape responses to it. With conceptual roots in anthropology and sociology the notion of habitus provides a means of acknowledging the historical dimensions of a social interaction situated within a specific place and time. Human subjects are shaped by their socialisation and life experience, for example as this may be determined by their socio-economic position in society and their experience of education. While free to make choices, the choices made are likely to be strongly influenced by a subjective and taken-for-granted understanding of what is possible. Limits imposed by external structures will have been subconsciously internalised and so individuals have a tendency to conform to societal norms. Individual behaviour is thus shaped by habitus as well as determined by conscious choices and actions; and this means there is a tendency for the status quo to be reproduced and for social structures to endure through time. Habitus thus implies a 'sense of one's place'; and also a 'sense of the place of others' (Bourdieu, 1989:19) while blocking a more objective perception of how advantage can be arbitrarily bestowed by social structures and norms.

The power of structures such as education systems was also a focus for Bourdieu and one which is particularly relevant to the action research discussed below. He described the 'symbolic capital' conferred by academic credentials such as degrees and used the term 'symbolic violence' to convey how, for example, universities and other pedagogic authorities are the arbiters of academic values and control the dispensing or withholding of academic credentials both formal - such as degrees and informal - such as 'graduateness'. Symbolic powers, maintains Bourdieu (1989:22), 'aim at imposing the vision of legitimate divisions, that is, at constructing groups' (original italics). Lefebrve (1991) posited the social production of space and outlined how dominant patterns of power may be reproduced within it; Massey (2004:254) affirmed that 'space is constituted through social relations and material social practices.'

We have identified conceptual frameworks, then, for understanding how subjective and immediate perceptions of being in an environment can intersect with historically internalised models of social structures and the 'place' one inhabits therein, and can bring these to bear on a discussion of this aspect of practical action research with our practitioner/academic research network. It should be understood that those members described here as 'practitioners' have almost all studied at degree level, and many at postgraduate level. Their present employment is in the world of 'practice' in the fields of education or social welfare.

\section{Research and Practice Networks}

Research and practice networks generally aim to work across the boundaries separating academia from practice, (in the case of this research, practice in the fields of education and social care). Appleby and Hillier (2012:33) state that such networks 'focus on aligning research with practice by generating research questions from practice and then applying research insights from findings,' and that they aim to 'generate practitioner insight to contribute to the wider body of professional knowledge' and to provide the wider critical debate and inquiry needed to support "questioning" rather than "knowing" practitioners' (Appleby and Hillier 2012:2). Research and practice networks are similar in nature to knowledge networks, and it is 
considered good practice that they should be underpinned by democratic principles (Seeley and Urquhart, 2008; Appleby and Hillier, 2012). The network under discussion here was set up by academics working at a University College in the south of England, and an interview with one of two founders confirmed that this was done with the intention of providing a fertile research environment for postgraduate students and also, a channel to convey reflections on and insight from the practice experience of the newly formed 'Children's Workforce' (Department for Education and Skills, 2005) to academic staff. It had been originally described in a statement of aims and objectives as 'a community of practice with democratic values' founded in order to 'promote and develop research activity amongst a range of practitioners and academics working in the social welfare professions.' It had been named the Research and Practice Network (RAPN). Over time, active membership of the network had dwindled and although it had about 100 addresses listed on its email database, most of these individuals had been enrolled by default (due to having been previously enrolled on a Masters level course in Professional Practice) rather than actively opting in to membership. The network met three times a year, and attendance at meetings, which had been originally around 30, had dwindled to around 8 . This normally included 2 or 3 members of academic staff, one of whom might give a presentation on a research project they had been involved in. From time to time, a member currently practising in the field of social welfare or education would present a research project they had undertaken.

The historical context of this network was problematic in the sense that it had been initially created by academic staff for the benefit of postgraduate students who were working locally in education or social care. Membership was automatically conferred on students, rather than their opting to join independently. There was a need to take steps to minimise the academic/student dynamic and foster a more democratic interaction, as this contribution from a past student/practitioner makes clear:

My first experience of the RAPN was a bit intimidating. A member of the academic staff wanted to have a discussion about her doctoral research. She asked us to comment on her plans, but how could we? I didn't know what to say, I didn't even have a Masters degree, and none of us said anything ...

\section{Action Research}

The research was conceived as a practical action research project (Zuber-Skerrit and Perry, 2002) by the convenor of the network, in response to a gradual decline in attendance at meetings. The research process aimed to reinvigorate the network and to discover whether it could function as originally intended, that is as a forum for sharing experiences of practitioner research, transferring knowledge and enabling peer discussion and mutual support in undertaking research projects. Action research has been the preferred approach to network-building for many (Chisholm, 2001; Richardson and Cooper, 2003; Seeley and Urquhart, 2008) and community action research has been discussed by Senge and Scharmer in terms of enabling an approach to collaborative knowledge generation which challenges 'traditional, fragmented consulting and academic research' (2001:196). As action research, the process necessarily involved members of the network; and since the focus of the network itself was 'research and practice' this had an extra resonance. Carrying out the 
research presented an opportunity to both model research processes (Reason and McArdle, 2004:3) and directly involve network participants in contributing to the process or reinvigoration.

The research employed methods including an emailed survey of contacts on the membership database, statistical analysis of data, interviews, observation, dialogue and reflective journal recordings. The period of research lasted for 16 months and the most intensive periods were centred around face to face network meetings, which took place at four-monthly intervals: so a total of four meetings were included in the research. Coughlan and Brannick (2010) describe a series of four-stage action research cycles, all of which are collaborative, comprising constructing, a dialogic stage in which a shared understanding of the issues is developed; planning action which is also a collaborative activity; taking action where plans are implemented; and finally evaluation, which leads into the subsequent cycle. They note that a single meeting can constitute an action research cycle, and this was felt to be the case here. This was in part due to the 'churn' in attendance, which meant that there were firsttime attendees at each meeting, and that for many people, attendance was a one-off event. Over the 4 meetings for which detailed data were collected, just one person attended all 4 meetings; 3 attended 3; 4 people attended twice, and 24 attended just once, perhaps because they had a particular interest in the research projects scheduled on the agenda for the day rather than an interest in becoming involved in the longer term.

Members made use of face-to-face meetings to make a number of suggestions for revitalising the network, many of which were acted on to good effect; these included sending out an e-flyer and inviting recipients to pass this on (potentially 'snowballing' recruitment); setting meeting dates well in advance and publicising these; aiming for a less formal workshop style in meetings; and allowing time for discussion of issues from the field at every meeting. Members would be invited to nominate agenda items whenever they were reminded by email of an approaching meeting date.

The membership email database was used in order to undertake a web-based survey. The survey was administered using a software system subscribed to by the University College and was piloted twice; suggestions made at a network meeting had also been incorporated in the survey design. The final version was emailed out to approximately one hundred addresses and generated seventeen responses (17\%), which tended to have come from those who were currently active in the network. The survey found that all respondents were working in the fields of social welfare/education. Respondents gave details of research interests that they would be share with other members, and listed areas of practice and research that they would like to explore further through network meetings. These included the impact of social media on youth culture and youth work; to update knowledge of research approaches; to learn more about consultation approaches and their efficacy; the impact of prevention work on various populations with regard to sexual health; the health benefits of using green spaces; the interface between statutory agencies and the third sector; and the application of research to service design/delivery. Ten respondents chose 'workshop' as their preferred method of face to face learning/exploration, as opposed to three who chose 'presentation.' This finding informed the style of subsequent meetings. Some respondents noted areas of practice they would like to be researched by students. While ten respondents expressed a desire for meetings to be held at the University College, there were two expressions of interest in attending 
meetings at different locations, two offers to host meetings at their own organisation, and four expressions of interest in visiting other projects within the South West.

Responses to a question about potential use of a network website were enthusiastic, with $92 \%$ of respondents agreeing that they would use such a website for viewing forthcoming events, $77 \%$ for inviting students to research areas of practice in which the respondent was involved, $69 \%$ for accessing past presentation, and 53\% for participating in themed conversations with other members. Only $46 \%$, however, agreed with the statement that they would use a website 'to contact practitioners in order to discuss potential research which I might carry out as part of my studies' this being one of the core purposes of the network at its inception. It is likely that this response was due to the preponderance of practitioners amongst the respondents, and had the wording been inclusive of practitioner as well as academic research this question might have generated a more positive response.

\section{Space and Place for Network Meetings}

One particular observation of a network meeting prompted a change in the customary practice of holding meetings at the University College. The custom was for members to meet for an informal lunch and then a more formal meeting in one of the institution's many teaching rooms. This would be furnished with the standard paraphernalia of a formal education setting: functional tables and chairs together with a fixed whiteboard and projector, and perhaps a flipchart. The tables would usually be arranged in a U - shape with the whiteboard at the 'head' - what has been described by Cox et al (2012:698) as 'classroom layout affirming a teacher-centric, transmissive micro-design.' As noted above, Harre (1993) found that people generally respond to the cues of a formal setting by adapting their behaviour in order to conform to the demands of the setting. Similarly, Whitchurch (2010) in her study of a community / business partnership, reports a tendency for professional and academic university staff to revert to the dominant 'rules and resources' (Giddens, 1991) implied by the institution. While academic staff were always welcoming towards practitioner-members, there was very much a sense that this was their home territory (Becher and Trowler, 2001). Harre used the term 'umwelt' to denote the 'socially significant environment', and noted that this 'includes many non-structural features' (1993:150). These features can be temporal, such as the ringing of a bell denoting the start of a class; they can also be physical boundaries, unseen boundaries (for example between a 'safe' and a 'dangerous' neighbourhood, or a social barrier such as membership or non-membership of an organisation). A recorded observation, which details the moment where the functioning of meetings became perceived as problematic by the researcher, is captured here in the form of a vignette, and illustrates many of the theoretical understandings mentioned above:

As people enter the teaching room, staff members greet their ex-students with affection. Past student achievements are recalled, somebody is given a hug; and as these exchanges are all led by the staff, we are reminded of the earlier student/tutor relationship. Staff members sit together en bloc. An ex-student, visibly nervous, presents a summary of her practitioner research to the group. She is encouraged by an authoritative member of staff, and kindly admonished for her modesty and diffidence during the presentation. After the presentation and ensuing discussion, the staff 
members rise from their seats together: now they must go and teach, so cannot stay for the remainder of the meeting.

The remaining group seems to relax and the discussion flows, now involving wider participation around the table. As the meeting eventually draws to a close, a first-time attendee reflects 'I really enjoyed it; at first I thought it wasn't for me, but it really is,'

The early stages of the interaction described in the vignette above could be understood in terms of what Bourdieu (1989:16) described as 'strategies of condescension ... by which agents who occupy a higher position in one of the hierarchies of objective space symbolically deny the social distance between themselves and others' while at the same time, practitioners tended to assume a more passive and at times deferential position: thus the behaviours of the two groups tended to 'co-specify' each other (Mannion, 2007:410) and as Thrift (2004:69) suggests, potentially losing a great deal in the process:

'it is quite clear that there are enormous emotional costs and benefits for individuals or groups in being shaped by particular institutions in particular ways. However, it is often quite difficult to show what is at stake for the individual or groups in submitting to such institutions and embracing certain affective styles that render them deferential, obedient or humble - or independent, aggressive and arrogant.'

It is worth reflecting here on the notion of 'symbolic violence' having been enacted during this exchange. If we consider this to be the case, it is not likely to have been intentionally done; which emphasises, as do Thrift's ideas above, that the more privileged group also lose in the process. Similarly, Freire's (1970) discussion of oppressed and oppressor positions acknowledges that both groups lose through the imbalance of power. 'Symbolic violence' is often enacted without being perceived by those whom it disadvantages, because to the disadvantaged, the education system may appear to be a largely neutral system which affords opportunities to all (Jenkins, 2002). It's quite likely that the non-academics present during the interaction were not conscious of the power dynamics perceived by the researcher, but were still affected by them. This is borne out by the responses to the survey discussed below, where a majority of respondents answered that they would be happy to attend meetings on the campus.

Other researchers have identified similar differentials in behaviour between academics and practitioners: Cunningham (2008) explored cultural differences between academic staff and the criminal justice practitioners with whom they engaged in a collaborative action research project in the USA. Here, practitioners reported a tendency for academic staff to talk, but not to listen to agency workers, together with differences in time-frames and depth of focus with the academic staff seeming to have more time and a greater willingness to analyse in depth. 'Lofty' academic language was also found to cause difficulties in understanding (Cunningham, 2008; Hart and Woolf, 2006).

An awareness of the 'power-geometry of intersecting trajectories' (Massey, 2004:64) underpinning the meeting described above would suggest that these dynamics may act to undermine the more democratic ethos which has been identified above as beneficial to the functioning of a research/practice or knowledge exchange 
network. This would not be surprising, given that many practitioners were re-entering the very environment in which they had previously submitted to a regime which graded and judged the worth of their academic work using a formal system. They could be understood, using the perspective of Freire (1970, [2000]) to have internalised the values of the hierarchy which had educated and regulated them. Those members who were not graduates of the institution would still be likely to recognise and respond to the cues implicit in the layout of the room and to the high status often accorded to academic staff, or implied by their behaviour.

In response to the online survey sent out to network members, $92 \%$ of respondents indicated that they would make use of a virtual space in order to, amongst other things: participate in themed conversations; broker research to be undertaken by current graduate or final-year students; and to make contact with fellow members of the network in between formal meetings. Aside from the convenience of providing an online forum in which to network, on-line communication has been found to level barriers of status between participants (Russell et al, 2004). Richardson and Cooper (2003) found that power and status inequalities between students and academics were less apparent online, where students were more familiar with 'netiquette' than their lecturers, and the virtual space was 'settled' predominantly by students. A similar effect is noted by Polin (2010). However, when a website was created for the RAPN, it was rarely accessed and the blogging facility was never used. The literature tends to show that where knowledge networks have engaged usefully with on-line communication, this has been in cases where resources have been heavily invested in maintaining, hosting and mediating the connections between users of the virtual network, by involving mentors, facilitators and online moderators in the process (Russell et al, 2004; Thang, 2011). The RAPN website was not supported in this way; the Network was provided with little or no staff resource. One member of the network observed that the lack of on-line engagement could have been a reflection of the age of members, most of whom were still developing their understanding of online communication.

Survey results also indicated that network members preferred a workshop-style discussion rather than the more traditional presentation of research. It was thought this was likely to be helpful in terms of encouraging a more participative style at meetings, avoiding the more formal configuration of presenter and audience. In terms of venue, Hart and Woolf (2006) highlight the importance of symbolic space in community/university partnerships and the implicit expectation of academics that community practitioners should always come to them. Ten respondents to the survey expressed a wish to attend meetings at the University College, but at the same time there were two expressions of interest in attending meetings at varied locations, two offers to host meetings in the respondent's own workplace, and four expressions of interest in visiting other projects. The penultimate meeting of the research period was the first to take place away from the University College campus.

This meeting took place in a community day facility for people who had experienced difficulties with substance use. It was situated in a semi-industrial waterfront location and was not easy to locate; once found, there was plenty of parking space and each arrival could be observed by a cluster of smokers gathered outside the building. The receptionist, an ex-service user, acted as gatekeeper in terms of providing directions, signing visitors in and arranging their access to staff and premises. In terms of symbolic power, there was a sense that this resided with service users and staff, and that the values embodied here might be of a very different 
nature to those of the more formal and hierarchical academic institution. The meeting room provided for our use was functional; like the university teaching room it was furnished with tables, chairs and flip chart but it was flexible in design and all of the equipment and furnishings could be moved and reconfigured to suit a range of uses; unlike the university teaching room the material space and furnishings did not specify hierarchical roles (Gum et al, 2012). The meeting held in this space was the most successful of the research period in terms of participation (following the presentation of a research project in progress, all attendees contributed to the discussion, including 4 members who were attending for the first time, in contrast to the passive participation style of many members when meetings had been held on the University College campus). It could be argued that meeting at a venue where only one member of the group was on their own territory, a venue which had metaphorically come up from the street rather than down from its ivory tower, may have enabled the network at that point in time and space to embrace a more democratic mode of operation than when situated within a Higher Education campus. It was hoped that this process of democratisation would be strengthened by the newly adopted practice of the host taking on the role of facilitator or chair of the meeting.

Subsequently, the group became more nomadic, meeting at a variety of venues both in community settings and in meeting (rather than teaching) rooms on the University College campus. Unfamiliar venues sometimes proved difficult to find, but informal conversations with members indicated that 'the RAPN is better now,' and that 'it does feel different.' However, in the face of increasing financial austerity and staffing cutbacks, it was becoming more difficult for both academic staff and those practising in the field to find or justify time to attend meetings which were not seen to directly contribute towards key tasks and targets, and the Network is not currently functioning.

\section{Conclusion}

This paper has focused on the influence of setting on the meetings of a research and practice network. It has sought to bring a social relational understanding of space to an examination of the behaviours of community-based practitioners (many of them graduates of the host institution) and academics. Findings suggest that using a range of venues, and avoiding Higher Education teaching rooms, may enable all members to become less prone to reverting to historical, hierarchical role-behaviours (Harre, 1993) and to engage more freely in order to further the development of the network as a whole. Situating a meeting in a community workplace might not impact on the habitus (Bourdieu, 1989) of participants, but it does emphasise and validate the work taking place outside the world of academia, emphasising the 'practice' element of the Research and Practice Network. The use of a virtual space was endorsed by members, but not used in practice.

It would be simplistic, however, to take from this research the message that the implicit and embodied power of the university campus is likely to crush innovation and silence partners from 'the community' who are engaged in continuing professional development and practitioner research. Practitioner members of the RAPN expressed enthusiasm for their link with the host institution:

I hope that we can access the library, and that the network can act as a link between heady academia and the grind of being in practice. I believe that lecturers and academic staff can benefit by staying more in touch with the 
wider sector and that practitioners can stay in touch with the ideals of research, theory and ideas. Please continue the network. (Survey respondent)

Belonging to the network may be valued in part for the contribution it can make to members' sense of professional identity. Cunningham (2008) found that in collaborative action research, practitioners with higher degrees valued their association with academic researchers, though this association could also bring about anxiety. Hart and Wolff (2006) found that practitioners can place 'huge' symbolic value on honorary membership of a university and also appreciate the rich practical resources this association can bring in terms of desk space, library, computer and online resources together with the prestige of the location; they found visits to the campus also raised the self-esteem of some groups and concluded that collaborators should spend time together, both on- and off-campus.

Identity is constructed in social contexts and is affected by feelings of belonging in particular places and with particular people. From some of the qualitative data gathered, it seems that to 'core' members, (who regularly attended most meetings) membership of the research network represented a peripheral but significant and valued element of their professional identities. Wenger (1998:149) discussed 'identity as a nexus of multimembership (original emphases), in which we define who we are by the ways in which we reconcile our various forms of membership into one identity.' Practitioner members of the network were all graduates, and valued the opportunity offered by the meetings to critically reflect on practice and to link it with theoretical concepts. In the current fiscal and policy climate it becomes increasingly difficult for practitioners to make time to attend non - instrumental meetings, and professionals may struggle with 'conflicting forms of individuality and competence as defined in different communities' (Wenger, 1998:160): they often reported that their employing organisations seemed not to value critical reflective practice but rather preferred to work with more compliant employees. Anecdotal evidence gained in conversation with network members indicates that they may have felt that 'I just can't justify the time any more' 'My manager's only interested in me getting the work done.' Alvesson and Wilmott (2002) discuss the influence of the workplace in terms of regulating identity, versus the individual's identity work, which relates to Giddens' (1991:32) 'reflexive project of the self'. It seems plausible that for the core members of the network, meetings whether hosted by the university or in the workplace, provided a critical space within which to explore the tensions and dilemmas of reconciling core shared values with the realities and compromise of current practice in the world of work. Membership of the network, with its associations of academic freedom and autonomy, could have been perceived symbolically to represent 'a crack of agency in the concrete of social structure' (Wenger 2010:190).

In planning university/community partnerships and collaboration, then, it would be advisable to bear in mind the symbolic power of 'space and place' to set the tone for relationships between members. In doing so, one should be mindful of participants' 'habitus' and especially their experience of education in general and 'the academy' in particular. Attention may need to be paid to choice of venue, facilitation techniques and rotating roles in formal meetings, in much the same way as is deemed necessary in order to ensure effective interprofessional practice. 


\section{References}

Alvesson, M and Willmott, H (2002) 'Identity regulation as organizational control: Producing the appropriate individual' Journal of Management Studies 39,5: 619-644

Appleby, Y., and Hillier, Y (2012) 'Exploring practice - research networks for critical professional learning' Studies in Continuing Education 34, 1: 31-43

Barker, R. G. (1968) Ecological Psychology: Concepts and Methods for Studying the Environment of Human Behaviour. Stanford, CA: Stanford University Press

Bourdieu, P (1977) Outline of a Theory of Practice Cambridge: Cambridge University Press

Bourdieu, P (1989) 'Social Space and Symbolic Power' Sociological Theory 7,1: 14-25

Chisholm, R (2001) 'Action Research to Develop an Interorganizational Network' in Reason, P and Bradbury, H (eds) (2006) The Handbook of Action Research (Concise Paperback Edition) London: Sage

Coghlan, D and Brannick, T (2009) Doing Action Research in Your Own Organization. $\left(^{\text {rd }}\right.$ edn) London: Sage

Cunningham, W (2008) 'Voices from the field: practitioner responses to collaborative research initiatives.' Action Research 6, 4: 373-390

Department for Education and Skills (2005) Children's Workforce Strategy: a strategy to build a world-class workforce for children and young people Annesley: DfES [online] Avaliable at https://www.education.gov.uk/consultations/downloadabledocs/5958-dfesecm.pdf (accessed 14 Jan 2015)

Freire,P (2000 [1970]) Pedagogy of the Oppressed London: Continuum

Gum, L. F., Prideaux, D., Sweet, L. And Greenhill, J (2012) 'From the nurses' station to the health team hub: How can design promote interprofessional collaboration?' Journal of Interprofessional Care 26, 1, 21-27

Harre, R (1993) Social Being (2 nd $^{\text {edn }) ~ O x f o r d: ~ B l a c k w e l l ~}$

Hart, A and Wolff, D (2006) 'Developing local "Communities of Practice” through local community/university partnerships’ Planning, Practice and Research 21, 1: 121-138

Jenkins, R (2002) Pierre Bourdieu ( $2^{\text {nd }}$ edn) London: Routledge

Lefebvre, H (1991) The Production of Space Oxford: Blackwell

Lewin, K (1943/1997) 'Defining the" field at a given time"' in Lewin, G and Cartwright, D (eds) (1943) Resolving Social Conflicts: Field Theory in Social Science Washington: American Psychological Association pp 68-79

Lewin, K. (1948) Resolving social conflicts; selected papers on group dynamics. Lewin, G. W. (ed.)New York: Harper \& Row

Mannion, G (2007) 'Going Spatial, Going Relational: Why "listening to children" and children's participation needs reframing Discourse: studies in the cultural politics of education 28, 3: 405-420

Massey, D (2005) For Space London: Sage

Polin, L (2010) 'Graduate professional education from a community of practice perspective: The role of social and technical networking' in Blackmore, C (ed) Social Learning Systems and Communities of Practice. London: Springer

Reason, P and McArdle, K (2004) 'The theory and practice of action research' in Becker, S and Bryman, A (eds) (2004) Understanding Research for Social Policy and Practice Bristol: Policy Press 
Richardson, B and Cooper, N (2003) 'Developing a virtual interdisciplinary research community in Higher Education' Journal of Interprofessional Care 17, 2: 173-182

Russell, J, Greenhalgh, T, Boynton, P, and Rigby, M (2004) 'Information in practice: soft networks for bridging the gap between research and practice.' BMJ Vol 328 [Online] available at www.bmj.com/cgi/content/full/328/7449/1174 (accessed 5 May 2008).

Seeley, H and Urquhart, C (2008) 'Action Research in Developing Knowledge Networks' Health Informatics Journal 14,4: 279-296

Senge, P and Scharmer, O (2001) 'Community Action Research: Learning as a Community of Practitioners, Consultants and Researchers' in Reason, P and Bradbury, H (eds) (2006) The Handbook of Action Research (Concise Paperback Edition) London: Sage

Thang, S, Hall, C, Murugaiah, P, and Azman, H (2011) 'Creating and maintaining online communities of practice in Malaysian Smart Schools: challenging realities' Educational Action Research 19, 1:87-105

Thrift, N (2008) Non-Representational Theory: Space/politics/affect Abingdon: Routledge

Wenger, E (1998) Communities of Practice: Learning, Meaning and Identity Cambridge: Cambridge University Press

Wenger, E (2010) 'Communities of Practice and Social Learning Systems: the Career of a Concept' in Blackmore, C (ed) Social Learning Systems and Communities of Practice. London: Springer

Whitchurch, C (2010) 'Some implications of 'public/private' space for professional identities in higher education' Higher Education 60, 6: 627-640

Zuber-Skerritt, O and Perry, C (2002) 'Action Research within organisations and university thesis writing' The Learning Organization. 9, 4: 171-179 